\title{
Low Birth Weight and Associated Factors Among Newborn Babies in Health Institutions in Dessie, Amhara, Ethiopia
}

This article was published in the following Dove Press journal: Journal of Multidisciplinary Healthcare

\author{
Desalegn Abebaw Jember (D)' \\ Zeleke Argaw Menji \\ Yibeltal Asmamaw Yitayew $\mathbb{D}^{3}$ \\ 'Department of Pediatric Nursing, \\ St. Paul Hospital Millennium Medical \\ College, Addis Ababa, Ethiopia; ${ }^{2}$ College \\ of Nursing and Midwifery, Addis Ababa \\ University, Addis Ababa, Ethiopia; \\ ${ }^{3}$ Department of Pediatric and Child \\ Health Nursing, College of Medicine and \\ Health Science, Wollo University, Dessie, \\ Ethiopia
}

Background: Globally, more than 20.5 million infants are born with low birth weight, and the majorities were from Asia and Africa. Even though efforts were made to reduce low birth weight worldwide, it remains a global public health problem, especially in sub-Saharan Africa.

Objective: To assess low birth weight and associated factors among newborn babies in health institutions in Dessie, Amhara, Ethiopia.

Methods: An institution-based cross-sectional study was conducted among 358 newborn/ mother pairs from March 1 to April 15, 2017, in Dessie town health institutions. The data were collected using a semi-structured interviewer-guided questionnaire. The numbers of newborn/mother pairs surveyed from each health institution were allocated proportionally, and systematic random sampling was used to select the respondents. Epi-info version 7.0 was used for data entry, and Statistical Package for Social Sciences version 20 was used for the analysis. Multivariate logistic regression with adjusted odds ratios and 95\% confidence intervals were used to identify significantly associated variables with low birth weight.

Results: In this study, the prevalence of low birth weight was $15.6 \%$. Maternal age $<20$ years (AOR: 3.78, 95\% CI, 1.02-13.97), rural residence (AOR: 3.49, 95\% CI, 1.48-8.24), having antenatal care follow-up (AOR: 3.79, 95\% CI, 1.08-13.23), gestational age <37 weeks (AOR: 3.82, 95\% CI, 1.55-9.42), and females (AOR: 3.37, 95\% CI, 1.17-9.72) were significantly associated with low birth weight.

Conclusion: The proportion of LBW in this study is comparable to the estimated global prevalence. Maternal age, residence, antenatal care, gestational age, and sex were significantly associated variables with low birth weight. Therefore, special attention should be given to antenatal care services and preventive strategies for preterm delivery.

Keywords: birth weight, low birth weight, non-low birth weight, newborn, Ethiopia

\section{Introduction}

According to the World Health Organization (WHO), low birth weight (LBW) is a birth weight of $<2500$ grams irrespective of gestational age. ${ }^{1}$ Overall, it is estimated that $17.5 \%$ of births worldwide are $\mathrm{LBW}^{2}$ In 2015 , an estimated 20.5 million live births were LBW, and 91\% were from low and middle-income countries, mainly Southern Asia (48\%) and sub-Saharan Africa (24\%). ${ }^{2}$

Newborns with LBW are more likely to die prematurely compared to normal birth weight newborns. Some epidemiological observations revealed that infants born under-weight are 20 times more likely to die compared with normal-weight
Correspondence: Yibeltal Asmamaw Yitayew

Email yibie.asmamaw@gmail.com
Journal of Multidisciplinary Healthcare 2020:13 1839-1848

1839

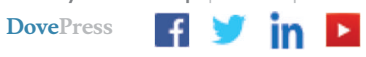

http://doi.org/10.214 
babies. ${ }^{3,4}$ Likewise, LBW babies experience more morbidity, both in the short and long term. Among these, respiratory distress, sleep apnea, heart problems, jaundice, anemia, chronic lung disorders, mental retardation, and cerebral palsy are the morbidities related to LBW newborns. ${ }^{5,6}$

Major risk factors associated with LBW are young mothers $(<20$ years), maternal body mass index $<$ $18 \mathrm{~kg} / \mathrm{m} 2$, rural residence, non-pregnant weight, primipara, previous histories of adverse birth outcomes, preterm delivery, history of delivering a preterm or small baby, premature rupture of membranes, maternal hypertension during pregnancy, anemia during pregnancy, presence of chronic medical illness, access to media (Television and Radio), lack of formal education, absence of antenatal care (ANC) follow-up, low socioeconomic status, prenatal exposure to ambient inhalable particle, and indoor parental smoking. ${ }^{4,7-14}$

Even though efforts were made to reduce the incidence of LBW worldwide, it remains a global public health problem, especially in sub-Saharan Africa. ${ }^{15}$ In lowincome countries where insufficient resources are allocated for health care services, the burden of LBW constitutes a significant public health issue. Likewise, in Ethiopia, LBW is a major public health problem. Even though only $14 \%$ of children in Ethiopia are weighted, different studies showed that the prevalence of LBW ranges from $6.3 \%-32.1 \%$. $^{3,9,16-18}$

Globally, there is a $30 \%$ reduction plan in the number of LBW live births compared to a baseline set in 2006-2010. ${ }^{19}$ To achieve this plan, epidemiological data on the magnitude and associated factors of LBW had a significant contribution to plan maternal and newborn care services. ${ }^{7}$ However, there is no study conducted in this regard in Dessie town health facilities. Therefore, this study aims to assess LBW and associated factors among newborn babies in Dessie town health institutions.

\section{Methods}

\section{Study Setting, Design and Period}

An institution-based cross-sectional study was conducted from March 1 - April 15, 2017, in Dessie town health institutions. Dessie town is the capital city of the South Wollo zone, which is located $401 \mathrm{~km}$ away from Addis Ababa and $480 \mathrm{~km}$ from Bahir Dar. In Dessie town, there is one public referral hospital, three health centers, and three private hospitals that provide maternal health services, and all these institutions were included in the study.

\section{Source and Study Population}

The source population was all newborn/mother pairs delivered in Dessie town health institutions, and the study population was all randomly selected newborn/mother pairs delivered in Dessie town health institutions from March 1 - April 15, 2017.

\section{Exclusion Criteria}

Newborn babies whose mother suffered from severe medical or surgical condition, twin delivery, and unknown last menstrual period with absent ultrasound evidence were excluded from the study.

\section{Sample Size Determination and Procedure}

The sample size was calculated using a single population proportion formula with the assumption of $32.1 \%$ prevalence of LBW babies at birth in Ethiopia with a 95\% confidence interval and 5\% marginal error. ${ }^{18}$

$$
\begin{aligned}
\mathrm{n}= & (\mathrm{Z} / 2) 2 \times \mathrm{p}(1-\mathrm{p}) / \mathrm{d} 2=(1.96) 2 \times(0.321) \\
& \times(0.679) /(0.0025)=335
\end{aligned}
$$

By considering a $10 \%$ non-response rate, the final sample size was 369 newborn/mother pairs. There are seven (four governmental and three privates) health institutions in Dessie town which provides delivery services. The numbers of newborn/mother pairs surveyed from each health institution were allocated proportionally based on the expected number of deliveries in the study period, which was estimated using the number of last six months' delivery in each institution.

The Proportional allocation was calculated using the following formula:

$$
n j=\frac{n}{N} N j
$$

where:

$n j=$ Sample size of the jth health institution

$\mathrm{n}=$ total sample size

$\mathrm{Nj}=$ number of newborn babies delivered at $\mathrm{jth}$ health institution in the study period

$\mathrm{N}=$ Total number of newborn babies delivered in all health institutions in the study period.

Finally, respondents were selected systematically $(k=3)$ based on the sequence of delivery until the required sample size was obtained (Figure 1). 


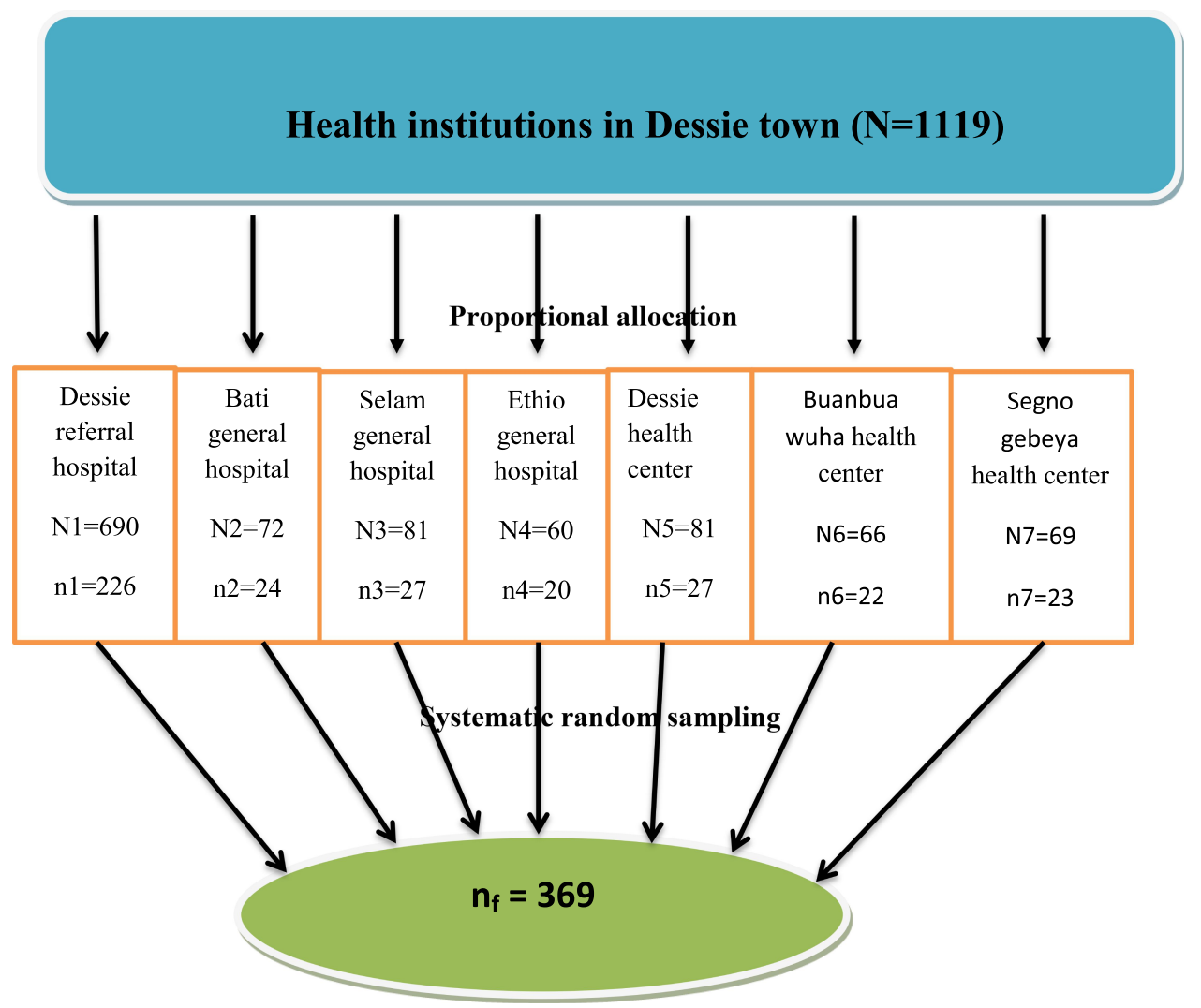

Figure I Schematic presentation of sampling procedure in Dessie town health institutions, Ethiopia, 2017 (N=358).

\section{Operational Definitions (Others) Birth Weight}

The first weight of the newborns, which was measured within 24 hours of birth.

\section{LBW}

Birth weight $<2500$ grams. ${ }^{1}$

\section{Gestational Age}

The duration of pregnancy from conception to delivery, which was determined by last menstrual period or ultrasound evidence.

\section{Pregnancy Complications}

Health problems that occur during pregnancy (antepartum hemorrhage (APH), premature rupture of membrane (PROM), pregnancy-induced hypertension (PIH), etc.).

\section{Anemia During Pregnancy}

Haemoglobin $(\mathrm{Hb})$ level $<11 \mathrm{~g} / \mathrm{dl}^{20}$

\section{Dietary Counseling}

Nutrition related advice provided to pregnant mothers by the health professionals.

\section{Data Collection Tool and Procedure}

The data were collected using a semi-structured and pretested interviewer-guided questionnaire that was adopted and modified from the studies conducted in the Ethiopian demographic health survey, Ethiopia, Algeria, and Ghana. ${ }^{9,16,21,22}$ The questionnaire comprises five sections: (I) sociodemographic factors, (II) maternal reproductive characteristics, (III) nutritional and behavioral factors, (IV) newborn factors, and (V) the outcome variable (LBW). The weight of the newborn was measured using a similarly calibrated balanced Seca scale and recorded to the nearest $100 \mathrm{~g}$. Mothers were interviewed in the postnatal ward, and medical records were also reviewed to obtain variables such as maternal obstetric and antenatal care history. The data were collected by seven trained midwives and supervised by two BSc midwives.

\section{Data Quality Assurance}

The questionnaire was first prepared in English and translated to Amharic, then back-translated to English by two language experts. One day training was given for data collectors and supervisors. Moreover, a pretest was conducted in 5\% (19) of the final sample size in Boro Meda 
Hospital. Furthermore, continuous supervision and daily checking were conducted by supervisors and principal investigators.

\section{Data Processing and Analysis}

The data were checked for completeness, cleaned, coded, and entered into EPI info version 7.0, and then exported to Statistical Package for Social Sciences (SPSS) software version 20 for analysis. Frequency, proportion and summary statistics were used to describe the study population. Bivariate logistic regression was used to assess the association of independent variables with the outcome variable, and variables that had a $p$-value $<0.2$ were further analyzed using multivariate logistic regression. Finally, odds ratios (ORs) with 95\% CIs were computed, and variables with a $\mathrm{p}$-value $<0.05$ were considered as significantly associated variables. The model fitness was checked with the Hosmer and Lemeshow goodness-of-fit test $(\mathrm{p}=0.435)$.

\section{Ethical Consideration}

Ethical clearance was obtained from Addis Ababa University College of Health Sciences, School of Allied Health Sciences, and official letters were submitted to each respective health facility. After explaining the objectives of the study, informed written consent was obtained from all mothers, and anonymity and confidentiality of the data were kept. Respondents have the right not to participate or withdraw from the study at any stage, and all study methods were performed in accordance with the Declaration of Helsinki.

\section{Result}

\section{Sociodemographic Factors of Respondents}

A total of 358 newborn/mother pairs were participated in the study, constituting a response rate of $97 \%$. The mean age and standard deviation of the mothers were $28.45 \pm 6.2$ years, and $70.7 \%$ were age groups from 20-34 years. The majority of mothers $(58.9 \%)$ were Muslims in religion, and $79.1 \%$ were Amhara in ethnicity. More than three-quarters of the mothers $(80 \%)$ were married, $78.8 \%$ were urban residents, and $42.5 \%$ were housewives. Regarding maternal educational status, $27.4 \%$ of the respondents were unable to read and write (Table 1).
Table I Socio-Demographic Factors of Mothers in Dessie Town Health Institutions, Ethiopia, $2017(\mathrm{~N}=358)$

\begin{tabular}{|c|c|c|c|}
\hline \multirow[t]{2}{*}{ Variables } & \multicolumn{3}{|c|}{ Number (\%) } \\
\hline & LBW & Non-LBW & Total \\
\hline \multicolumn{4}{|l|}{ Age of the mother } \\
\hline$<20$ & $9(2.5)$ & $39(10.9)$ & $48(13.4)$ \\
\hline $20-34$ & $35(9.8)$ & $218(60.9)$ & $253(70.7)$ \\
\hline $35-49$ & $12(3.3)$ & $45(12.6)$ & $57(15.9)$ \\
\hline \multicolumn{4}{|l|}{ Religion } \\
\hline Muslim & $44(12.3)$ & $167(46.6)$ & $211(58.9)$ \\
\hline Orthodox & II (3.I) & $169(47.2)$ & $130(36.3)$ \\
\hline Protestant & $\mathrm{I}(0.3)$ & $16(4.4)$ & $17(4.7)$ \\
\hline \multicolumn{4}{|l|}{ Ethnicity } \\
\hline Amhara & $46(12.8)$ & $237(66.2)$ & $283(79.1)$ \\
\hline Tigre & $8(2.2)$ & $53(14.8)$ & $61(17.0)$ \\
\hline Oromo & $2(0.6)$ & $12(3.3)$ & $14(3.9)$ \\
\hline \multicolumn{4}{|l|}{ Maternal educational status } \\
\hline Not read and write & $25(7)$ & $73(20.4)$ & $98(27.4)$ \\
\hline Read and write & $9(2.5)$ & $50(14)$ & $59(16.5)$ \\
\hline Primary education & $10(2.8)$ & $|I|(3 I)$ & $121(33.8)$ \\
\hline Secondary \& above & $12(3.3)$ & $68(19)$ & $80(22.3)$ \\
\hline \multicolumn{4}{|l|}{ Residence } \\
\hline Rural & $20(5.6)$ & $56(15.6)$ & $76(21.2)$ \\
\hline Urban & $36(10.1)$ & $246(68.7)$ & $282(78.8)$ \\
\hline \multicolumn{4}{|l|}{ Marital status } \\
\hline Single & $17(4.7)$ & $54(15.1)$ & $71(19.8)$ \\
\hline Married & $39(10.9)$ & $248(69.3)$ & $287(80.2)$ \\
\hline \multicolumn{4}{|l|}{ Mothers occupation } \\
\hline Farmer & $17(4.8)$ & $47(13.1)$ & 64 (17.9) \\
\hline Merchant & $9(2.5)$ & $73(20.4)$ & $82(22.9)$ \\
\hline House wife & $24(6.7)$ & $128(35.8)$ & $152(42.5)$ \\
\hline Gov't employee & $6(1.7)$ & $54(15.1)$ & $60(16.8)$ \\
\hline
\end{tabular}

\section{Maternal Medical and Reproductive Characteristics}

One hundred thirty-five (37.7\%) respondents were primiparous, and the majority (59.7\%) of mothers had a birth interval of $\geq 24$ months. Two hundred eighty-four (79.3\%) of the pregnancies were intended, and only $52(14.2 \%)$ had current pregnancy complications. Ten $(2.8 \%)$ respondents had a history of LBW, 309 (86.3\%) had ANC follow-up, and $301(84.1 \%)$ had taken iron and folic acid (IFA) supplementation during pregnancy. Additionally, 6.4\%, $1.4 \%$, and $2.5 \%$ of mothers had anemia, malaria, and sexually transmitted infections during pregnancy, respectively (Table 2). 
Table 2 Maternal Medical and Reproductive Characteristics in Dessie Town Health Institutions, Ethiopia, 2017 ( $N=358)$

\begin{tabular}{|c|c|c|c|}
\hline \multirow{2}{*}{ Variable } & \multicolumn{3}{|c|}{ Number (\%) } \\
\hline & LBW & Non-LBW & Total \\
\hline \multicolumn{4}{|l|}{ Parity } \\
\hline I & $18(5.0)$ & 117 (32.7) & I 35 (37.7) \\
\hline $2-3$ & $29(8.1)$ & $163(45.5)$ & $192(53.6)$ \\
\hline$\geq 4$ & $9(2.5)$ & $22(6.2)$ & $31(8.7)$ \\
\hline \multicolumn{4}{|l|}{ Birth interval (in months) } \\
\hline$\leq 24$ & $22(8.7)$ & $80(31.6)$ & $102(40.3)$ \\
\hline$>24$ & $16(6.3)$ & $135(53.4)$ & $15 \mid(59.7)$ \\
\hline \multicolumn{4}{|l|}{ Desirability of pregnancy } \\
\hline Yes & $36(10)$ & $248(69.3)$ & $284(79.3)$ \\
\hline No & $20(5.6)$ & $54(15.1)$ & $74(20.7)$ \\
\hline \multicolumn{4}{|l|}{$\begin{array}{l}\text { Current pregnancy } \\
\text { complication }\end{array}$} \\
\hline Yes & $16(4.4)$ & $35(9.8)$ & $5 I(14.2)$ \\
\hline No & $40(11.2)$ & $267(74.6)$ & $307(85.8)$ \\
\hline \multicolumn{4}{|l|}{$\begin{array}{l}\text { Types of pregnancy } \\
\text { complication }\end{array}$} \\
\hline APH & $3(5.9)$ & $7(13.7)$ & $10(19.6)$ \\
\hline PROM & $3(5.9)$ & $9(17.6)$ & $12(23.5)$ \\
\hline $\mathrm{PIH}$ & $10(19.6)$ & $19(37.3)$ & $29(56.9)$ \\
\hline \multicolumn{4}{|l|}{ History of LBW } \\
\hline Yes & $\mathrm{I}(0.3)$ & $9(2.5)$ & $10(2.8)$ \\
\hline No & $55(15.4)$ & $293(81.8)$ & $348(97.2)$ \\
\hline \multicolumn{4}{|l|}{ Chronic medical illness } \\
\hline Yes & $3(0.8)$ & $3(0.8)$ & $6(1.7)$ \\
\hline No & $53(14.8)$ & $299(83.5)$ & $352(98.3)$ \\
\hline \multicolumn{4}{|l|}{$\begin{array}{l}\text { Types of chronic medical } \\
\text { illness }\end{array}$} \\
\hline $\mathrm{TB}$ & I (16.7) & I (16.7) & $2(33.4)$ \\
\hline HIV & $2(33.3)$ & $2(33.3)$ & $4(76.6)$ \\
\hline \multicolumn{4}{|l|}{ Malaria during pregnancy } \\
\hline Yes & - & $5(1.4)$ & $5(1.4)$ \\
\hline No & $56(15.6)$ & $297(83)$ & $353(98.6)$ \\
\hline \multicolumn{4}{|l|}{ STI during pregnancy } \\
\hline Yes & $4(1.1)$ & $5(1.4)$ & $9(2.5)$ \\
\hline No & $52(14.5)$ & $297(83)$ & $349(97.5)$ \\
\hline \multicolumn{4}{|l|}{ Anemia during pregnancy } \\
\hline Yes & $14(3.9)$ & $9(2.5)$ & $23(6.4)$ \\
\hline No & $79(22.1)$ & $256(71.5)$ & $335(93.6)$ \\
\hline \multicolumn{4}{|l|}{ ANC follow-up } \\
\hline Yes & $39(10.9)$ & $270(75.4)$ & $309(86.3)$ \\
\hline No & $17(4.8)$ & $32(8.9)$ & 49 (13.7) \\
\hline
\end{tabular}

(Continued)
Table 2 (Continued).

\begin{tabular}{|c|l|l|l|}
\hline \multirow{2}{*}{ Variable } & \multicolumn{3}{|l|}{ Number (\%) } \\
\cline { 2 - 4 } & LBW & Non-LBW & Total \\
\hline $\begin{array}{c}\text { Trimester of ANC follow-up } \\
\text { Ist }\end{array}$ & $7(2.3)$ & $107(34.6)$ & $114(36.9)$ \\
2nd & $16(5.2)$ & $159(51.4)$ & $175(56.6)$ \\
3rd & $5(1.6)$ & $15(4.9)$ & $20(6.5)$ \\
\hline $\begin{array}{c}\text { Number of ANC follow-up } \\
\text { I-3 }\end{array}$ & $9(2.9)$ & $84(27.1)$ & $93(30.1)$ \\
$4+$ & $19(6.1)$ & $197(63.8)$ & $216(69.9)$ \\
\hline $\begin{array}{l}\text { IFA supplementation } \\
\text { Yes }\end{array}$ & $40(11.2)$ & $261(72.9)$ & $301(84.1)$ \\
No & $16(4.5)$ & $41(11.4)$ & $57(15.9)$ \\
\hline $\begin{array}{l}\text { Number of IFA tablets } \\
<60\end{array}$ & $14(4.7)$ & $160(53.1)$ & $174(57.8)$ \\
$60-90$ & $9(3)$ & $118(39.2)$ & $127(42.2)$ \\
\hline
\end{tabular}

\section{Nutritional Status and Behavioral Factors}

Three hundred thirty (92.2\%) mothers were counseled about dietary intake, and $290(81 \%)$ of them took extra meals during pregnancy. Nine (2.5\%) mothers smoked cigarettes, $19(5.3 \%)$ had drunk alcohol, and 31 (8.7\%) had chewed khat during pregnancy (Table 3).

\section{Newborn Factors}

The majority (63.4\%) of newborns were females, 282 (78.8\%) were gestational age $\geq 37$ weeks, and $5(1.4 \%)$ newborn babies had a visible birth defect (Table 4). The prevalence of LBW among newborn babies in Dessie town health institutions was $15.6 \%$ (95\% CI: $12.3 \%-19.8 \%)$ (Figure 2).

\section{Factors Associated with LBW}

In the bivariate analysis, the age of the mother, residence, marital status, parity, birth space, desirability of pregnancy, current pregnancy complication, anemia, having ANC follow-up, IFA provision, gestational age, dietary counseling during ANC visit, khat chewing, and sex had a p-value $<$ 0.2 . These variables were further analyzed using multivariate logistic regression, and the result showed that the age of the mother, residence, gestational age, having ANC follow-up, and sex of the newborns were significantly associated with LBW. 
Table 3 Nutritional and Behavioral Factors of Mothers in Dessie Town Health Institutions, Ethiopia, 2017 (N=358)

\begin{tabular}{|c|c|c|c|}
\hline \multirow[t]{2}{*}{ Variables } & \multicolumn{3}{|c|}{ Number (\%) } \\
\hline & LBW & $\begin{array}{l}\text { Non- } \\
\text { LBW }\end{array}$ & Total \\
\hline \multicolumn{4}{|l|}{ Dietary counseling } \\
\hline Yes & $45(12.6)$ & $285(79.6)$ & $330(92.2)$ \\
\hline No & II (3.I) & $17(4.7)$ & $28(7.8)$ \\
\hline \multicolumn{4}{|c|}{$\begin{array}{l}\text { Additional nutrition during } \\
\text { pregnancy }\end{array}$} \\
\hline Yes & $39(10.9)$ & $25 I(70.1)$ & $290(81.0)$ \\
\hline No & $17(4.7)$ & $51(14.3)$ & $68(19.0)$ \\
\hline \multicolumn{4}{|l|}{ Cigarette smoking } \\
\hline Yes & $2(0.6)$ & $7(1.9)$ & $9(2.5)$ \\
\hline No & $54(\mid 5 . I)$ & $295(82.4)$ & $349(97.5)$ \\
\hline \multicolumn{4}{|l|}{ Alcohol drinking } \\
\hline Yes & $6(1.7)$ & $13(3.6)$ & $19(5.3)$ \\
\hline No & $50(14)$ & $289(80.7)$ & 339 (94.7) \\
\hline \multicolumn{4}{|l|}{ Khat chewing } \\
\hline Yes & $10(2.8)$ & $21(5.9)$ & $31(8.7)$ \\
\hline No & $46(12.8)$ & $28 I(78.5)$ & $327(91.3)$ \\
\hline
\end{tabular}

Table 4 Newborn Factors of LBW in Dessie Town Health Institutions, Ethiopia, 2017 ( $N=358)$

\begin{tabular}{|l|l|l|l|}
\hline \multirow{2}{*}{ Variables } & \multicolumn{2}{l|}{ Number (\%) } \\
\cline { 2 - 4 } & LBW & Non-LBW & Total \\
\hline $\begin{array}{c}\text { Gestational age } \\
<37\end{array}$ & $24(6.7)$ & $52(14.5)$ & $76(21.2)$ \\
$\geq 37$ & $32(8.9)$ & $250(69.9)$ & $282(78.8)$ \\
\hline $\begin{array}{c}\text { Sex } \\
\text { Female }\end{array}$ & $43(12)$ & $184(51.4)$ & $227(63.4)$ \\
Male & $13(3.6)$ & $118(33)$ & $131(36.6)$ \\
\hline $\begin{array}{c}\text { Visible sever defect } \\
\text { Yes }\end{array}$ & - & $5(1.4)$ & $5(1.4)$ \\
No & $56(15.6)$ & $297(83)$ & $353(98.6)$ \\
\hline
\end{tabular}

Mothers aged $<20$ years old were 3.78 times more likely to deliver LBW newborns than 20-34 years old mothers (AOR: 3.78, 95\% CI, 1.02-13.97), and mothers lived in a rural area were 3.49 times more likely to deliver LBW babies compared with mothers who had living in the urban area (AOR: 3.49, 95\% CI, 1.48-8.24). Similarly, mothers who had no ANC follow-up during pregnancy were 3.79 times more likely to deliver LBW babies compared to mothers who had ANC follow-up (AOR: 3.79,

\section{Birth weight}

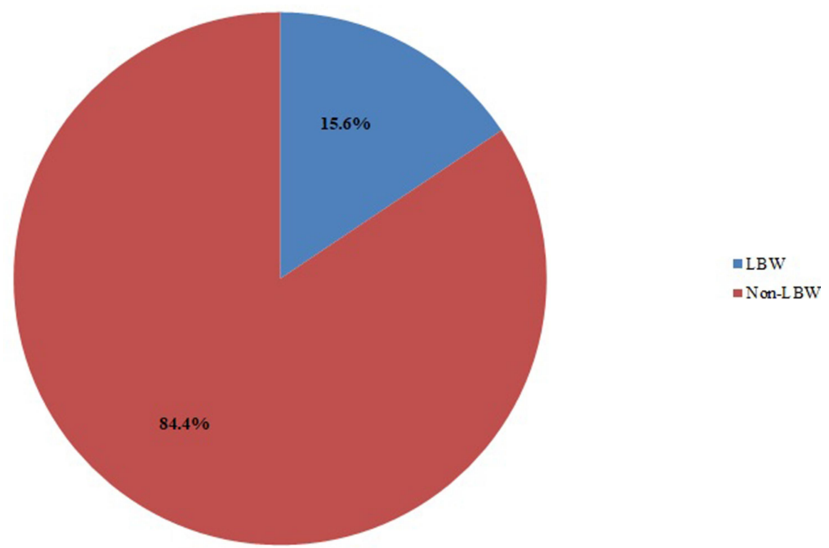

Figure 2 The prevalence of LBW among newborn babies in Dessie town health institutions, Ethiopia, 2017 ( $N=358)$.

95\% CI, 1.08-13.23). Newborn babies who were delivered before the gestational age of 37 weeks were 3.82 times more likely to be LBW compared to babies born in the gestational age of $\geq 37$ weeks (AOR: 3.82 , 95\% CI, 1.55-9.42). Finally, female newborn babies were 3.37 times more likely to be LBW than male newborns (AOR: 3.37 , 95\% CI, 1.17-9.72) (Table 5).

\section{Discussion}

The finding of this study showed that $15.6 \%$ of newborns were birth weight $<2500 \mathrm{~g}$. The age of the mother $<20$ years, residing in rural areas, preterm delivery $(<37$ weeks), attending ANC follow-up, and female sex were significantly associated variables to LBW.

The prevalence of LBW was $15.6 \%$ (95\% CI: $12.3 \%$ $-19.8 \%$ ). This finding was consistent with studies conducted in Gondar referral hospital (17.1\%), Tigray $(14.6 \%)$, a systematic review and meta-analysis in Ethiopia (17.3\%), Kenya (12.3\%), and the estimated global (17.5\%) and sub-Saharan African countries LBW prevalence $(16.4 \%)^{2,9,12,13,23}$ The reported value is higher than the study findings of Tigray $(6.3 \%$ and $9.9 \%)$, Nigeria (6.3\%), Iran (6.3\%), China (2.8\%), and the regional estimates of Central Asia (6\%), Eastern Asia (6\%), Western Asia (10.9\%), and Latin America and Caribbean $(8.8 \%)^{2,11,14,17,24}$ However, the prevalence of LBW was lower than studies conducted in Bahir Dar (21.2\%), Uganda (25.5\%), India (28.61\%), and the regional estimates of LBW in Southern Asia (32.3\%)., ${ }^{2,25,26}$ This difference might be due to the socioeconomic, seasonal, and geographical variation, which might result in 
Table 5 Binary and Multivariate Analysis of Factors Associated with LBW in Dessie Town Health Institutions, Ethiopia, 2017 (N=358)

\begin{tabular}{|c|c|c|c|c|c|}
\hline \multirow[t]{2}{*}{ Variable } & \multicolumn{2}{|l|}{ LBW } & \multirow[t]{2}{*}{ COR $[95 \% \mathrm{CI}]$} & \multirow[t]{2}{*}{ AOR $[95 \% \mathrm{Cl}]$} & \multirow[t]{2}{*}{ P-value } \\
\hline & Yes (\%) & No (\%) & & & \\
\hline \multicolumn{6}{|l|}{ Age of the mother } \\
\hline$<20$ & $9(16.1)$ & $39(12.9)$ & $1.44(1.6-3.22)$ & $3.78(1.02-13.97)^{*}$ & 0.047 \\
\hline $20-34$ & $35(62.5)$ & $218(72.2)$ & 1 & 1 & \\
\hline $35-49$ & $12(21.4)$ & $45(\mid 4.9)$ & $1.66(0.80-3.45)$ & $1.15(0.40-3.33)$ & 0.12 \\
\hline \multicolumn{6}{|l|}{ Residence } \\
\hline Rural & $20(35.7)$ & $56(18.5)$ & $2.44(1.30-4.50)$ & $3.49(1.48-8.24)^{*}$ & 0.04 \\
\hline Urban & $36(64.3)$ & $246(8 \mid .5)$ & 1 & I & \\
\hline \multicolumn{6}{|l|}{ Marital status } \\
\hline Single & $17(30.4)$ & $54(17.9)$ & $2.00(1.05-3.80)$ & $1.10(0.40-3.08)$ & 0.961 \\
\hline Married & $39(69.6)$ & $248(82.1)$ & 1 & 1 & \\
\hline \multicolumn{6}{|l|}{ Parity } \\
\hline 1 & $18(32.1)$ & $117(38.7)$ & 1 & 1 & \\
\hline $2-3$ & $29(51.8)$ & $163(54.0)$ & $2.66(1.06-6.68)$ & $2.33(0.5 I-10.75)$ & 0.454 \\
\hline$\geq 4$ & $9(16.1)$ & $22(7.3)$ & $2.30(0.96-5.49)$ & $3.88(0.60-25.02)$ & 0.227 \\
\hline \multicolumn{6}{|l|}{ Birth space (months) } \\
\hline$\leq 24$ & $22(57.9)$ & $80(37.2)$ & $2.32(1.15-4.68)$ & $2.18(0.92-5.19)$ & 0.09 \\
\hline$>24$ & $16(42.1)$ & $135(62.8)$ & 1 & I & \\
\hline \multicolumn{6}{|l|}{ Desirability of pregnancy } \\
\hline Yes & $36(64.3)$ & $248(82.1)$ & 1 & 1 & \\
\hline No & $20(35.7)$ & $54(17.9)$ & $2.55(1.37-4.75)$ & $1.49(0.57-3.91)$ & 0.585 \\
\hline \multicolumn{6}{|l|}{ Pregnancy complication } \\
\hline Yes & $16(28.6)$ & $35(11.6)$ & $3.05(1.55-6.01)$ & $2.67(0.86-8.28)$ & 0.15 \\
\hline No & $40(71.4)$ & $267(88.4)$ & 1 & 1 & \\
\hline \multicolumn{6}{|l|}{ Anemia during pregnancy } \\
\hline Yes & $14(60.9)$ & $9(39.1)$ & $3.19(1.28-7.93)$ & $0.87(0.17-4.56)$ & 0.80 \\
\hline No & $79(23.6)$ & $256(76.4)$ & 1 & 1 & \\
\hline \multicolumn{6}{|l|}{ ANC follow-up } \\
\hline Yes & $39(69.6)$ & $270(89.4)$ & 1 & 1 & \\
\hline No & 17(30.4) & $32(10.6)$ & $2.55(1.24-5.24)$ & $3.79(1.08-13.23)^{*}$ & 0.048 \\
\hline \multicolumn{6}{|l|}{ IFA provision } \\
\hline Yes & $40(71.4)$ & $26 \mid(86.4)$ & 1 & 1 & \\
\hline No & $16(28.6)$ & $4 I(13.6)$ & $2.55(1.31-4.96)$ & $0.66(0.19-2.31)$ & 0.53 \\
\hline \multicolumn{6}{|l|}{ Gestational age } \\
\hline$<37$ & $24(42.9)$ & $52(17.2)$ & $3.29(1.78-6.10)$ & $3.82(1.55-9.42)^{*}$ & 0.001 \\
\hline$\geq 37$ & $32(57.1)$ & $250(82.8)$ & 1 & 1 & \\
\hline \multicolumn{6}{|l|}{ Dietary counseling } \\
\hline Yes & $45(80.4)$ & $285(94.4)$ & 1 & 1 & \\
\hline No & $11(19.6)$ & $17(5.6)$ & $4.10(1.80-9.31)$ & $0.66(0.13-3.4 I)$ & 0.65 \\
\hline \multicolumn{6}{|l|}{ Khat chewing } \\
\hline Yes & $10(17.9)$ & $21(7.0)$ & $2.91(1.29-6.57)$ & $1.77(0.52-6.04)$ & 0.30 \\
\hline No & $46(82.1)$ & $281(93.0)$ & 1 & 1 & \\
\hline \multicolumn{6}{|l|}{ Sex of the new-born } \\
\hline Female & $43(76.8)$ & $184(60.9)$ & $2.12(1.09-4.11)$ & $3.37(1.17-9.72)^{*}$ & 0.018 \\
\hline Male & $13(23.2)$ & $118(39.1)$ & 1 & 1 & \\
\hline
\end{tabular}

Notes: *Statistically significant at $\mathrm{p}$ value $<0.05$ with $95 \% \mathrm{Cl}$. 
discrepancies in health service utilization and the nutritional status of mothers.

Mothers aged $<20$ years old were 3.78 times more likely to deliver LBW newborns than 20-34 years old. Likewise, studies conducted in Hosanna town, Gondar, Mekelle, and a systematic review and meta-analysis in Ethiopia showed similar findings. ${ }^{10,23,25,27}$ These might be because having a birth at an early age had a higher risk of delivering a baby with LBW. ${ }^{28}$ Pregnant teens are more likely to develop pregnancy-related high blood pressure and anemia, which will lead to preterm labor and delivery. Additionally, young women had less awareness of pregnancy-related problems and less likely to seek medical care as early as possible. ${ }^{29}$

Mothers who reside in rural areas had 3.49 higher odds of delivering LBW babies compared to urban residents. Studies conducted in Bahir Dar, Hosanna, Tigray, and Ghana reported similar findings. ${ }^{3,5,9,21}$ The possible reason might be the greater hardship due to poor infrastructures, hard physical work, and less access to basic health services in rural areas. Additionally, there will be lower accessibility for health information, health services utilization, and nutritional awareness in rural areas. ${ }^{30,31}$

The odds of LBW were 3.79 times higher in mothers who had no ANC follow-up compared to mothers who had ANC follow-up. This result is comparable with studies conducted in Bale zone hospitals, the University of Gondar, Hosanna town, and Mekelle. ${ }^{5,10,13,27}$ There will be a chance for monitoring of fetal wellbeing and timely intervention of feto-maternal problems when there is an ANC visit. Additionally, there will be routine nutritional and medical advice, as well as the provision of supplementations during ANC visits.

Newborns delivered in $<37$ weeks of gestation were 3.82 times more likely to be LBW than those who were delivered in $\geq 37$ weeks. Similar findings were reported from studies conducted in Dangla Ethiopia, a systematic review and meta-analysis in Ethiopia, Kenya, Uganda, Nepal, and India. ${ }^{12,23,25,32-34}$ Gestational age plays a significant role in determining infants' birth weight. Prematurely $(<37$ weeks) delivered newborns are at a higher risk of LBW. ${ }^{15,28,35}$

Finally, female newborns were 3.37 times more likely to be LBW compared to male newborns. This study is comparable with studies done in Kenya and India. ${ }^{12,32}$ The possible explanation would be female fetuses are insulin resistant than boys; as a result, they would not use glucose properly as males do during the intrauterine period. ${ }^{36}$

\section{Limitations of the Study}

Factors like intrauterine infection during pregnancy, placental abnormalities, pre-pregnancy weight, indoor environmental factors, outdoor air pollution, climatic factors, and seasonal variation were not addressed in this study. Additionally, this study will be subjected to recall bias.

\section{Conclusion}

The reported proportion of LBW in this study is comparable with the estimated global prevalence. Age of the mother $<20$ years, rural residence, absence of ANC follow-up, gestational age $<37$ weeks, and being female were significantly associated variables with LBW. Therefore, the Zonal health bureau and health care providers should have special attention to ANC services and preventive strategies for preterm delivery giving due attention to rural residing mothers.

\section{Abbreviations}

ANC, antenatal care; AOR, adjusted odds ratio; BSc, Bachelor of Science; CI, confidence interval; IFA, iron and folic acid; LBW, low birth weight; SPSS, Statistical Package for Social Sciences; WHO, World Health Organization.

\section{Data Sharing Statement}

The data used to support the findings of this study are available from the corresponding author upon request.

\section{Acknowledgments}

We would like to acknowledge Addis Ababa University for covering the cost of the research, and our special thanks goes to study participants, data collectors, supervisors, and staff of health institutions for their willingness to take part in the study. This paper was presented as a thesis to Addis Ababa University, School of Nursing and Midwifery, Department of Pediatric Nursing in May, 2017 and available online in the university's repository. ${ }^{37}$

\section{Funding}

Addis Ababa University had covered the costs for data collection instruments, data collection, data collectors, and supervisors, but the funder had no role in the decision to publish.

\section{Disclosure}

The authors declare that they have no conflicts of interest. 


\section{References}

1. Cutland CL, Lackritz EM, Mallett-Moore T, et al. Low birth weight: case definition \& guidelines for data collection, analysis, and presentation of maternal immunization safety data. Vaccine. 2017;35 (48):6492. doi:10.1016/j.vaccine.2017.01.049

2. Blencowe $H$, Krasevec J, de Onis M, et al. National, regional, and worldwide estimates of low birthweight in 2015, with trends from 2000: a systematic analysis. Lancet Glob Health. 2019;7(7):e849e860. doi:10.1016/S2214-109X(18)30565-5

3. Getachew G, Teumay A, Belaynew W, Berhe D. Incidence of low birth weight babies and associated factors among post-partum mothers who gave birth at Felege hiwot referral hospital, Bahirdar, Ethiopia. World J Pharm Pharm Sci. 2015;4:152-165.

4. Rajeswari R, Burman B, Sundar J, Ramya K. Trends in birth weight and the prevalence of low birth weight in a tertiary care hospital, Chennai. J Dental Med Sci. 2015;14(8):07-13.

5. Abdo R, Endalemaw T, Tesso F. Prevalence and associated factors of adverse birth outcomes among women attended maternity ward at Negest Elene Mohammed Memorial General Hospital in Hosanna Town, SNNPR, Ethiopia. J Women's Health Care. 2016;5:4.

6. Tripathy P. Clinical characteristics \& morbidity pattern among low birth weight babies. Age. 2014;20:20-30yrs.

7. Adane AA, Ayele TA, Ararsa LG, Bitew BD, Zeleke BM. Adverse birth outcomes among deliveries at Gondar University hospital, Northwest Ethiopia. BMC Pregnancy Childbirth. 2014;14(1):90. doi:10.1186/1471-2393-14-90

8. Alemu T, Umeta M. Prevalence and determinants of small size babies in Ethiopia: results from in-depth analyses of the Ethiopian demographic and health survey-2011. Fam Med Med Sci Res. 2015;4 (3):243-250.

9. Gebremedhin M, Ambaw F, Admassu E, Berhane H. Maternal associated factors of low birth weight: a hospital based cross-sectional mixed study in Tigray, Northern Ethiopia. BMC Pregnancy Childbirth. 2015;15(1):222. doi:10.1186/s12884-015-0658-1

10. Demelash H, Motbainor A, Nigatu D, Gashaw K, Melese A. Risk factors for low birth weight in Bale zone hospitals, South-East Ethiopia: a case-control study. BMC Pregnancy Childbirth. 2015;15 (1):264. doi:10.1186/s12884-015-0677-y

11. Mirzarahimi M, Hazrati S, Ahmadi P, Alijahan R. Prevalence and risk factors for low birth weight in Ardabil, Iran. Iran J Neonatol. 2013;4 (1):18-23.

12. Muchemi OM, Echoka E, Makokha A. Factors associated with low birth weight among neonates born at Olkalou District Hospital, Central Region, Kenya. Pan Afr Med J. 2015;20:1. doi:10.11604/ pamj.2015.20.108.4831

13. Zeleke BM, Zelalem M, Mohammed N. Incidence and correlates of low birth weight at a referral hospital in Northwest Ethiopia. Pan Afr Med J. 2012;12(1).

14. Lu C, Zhang W, Zheng X, Sun J, Chen L, Deng Q. Combined effects of ambient air pollution and home environmental factors on low birth weight. Chemosphere. 2020;240:124836. doi:10.1016/j.chemosphere. 2019.124836

15. WHO. WHA global nutrition targets 2025: low birth weight policy brief; 2014. Available from: https://www.who.int/nutrition/topics/glo baltargets_lowbirthweight_policybrief.pdf. Accessed 2017.

16. Central Statistical Agency - CSA/Ethiopia, ICF. Ethiopia Demographic and Health Survey. Addis Ababa, Ethiopia: CSA and ICF;2017; 2016.

17. Teklehaimanot N. Prevalence and factors associated with low birth weight in axum and laelay maichew districts, North Ethiopia: a comparative cross sectional study. Int J Nutr Food Sci. 2014;3 (6):560-566. doi:10.11648/j.jijnfs.20140306.21

18. Betew W, Muluneh EK. Determinants of low birth weight among children aged 0 to 59 months in Ethiopia. Int J Pure Appl Sci Technol. 2014;25(1):14.
19. Organization WH. Global Nutrition Targets 2025: Policy Brief Series. World Health Organization; 2014.

20. WHO Reproductive Health Library. WHO Recommendation on the Method for Diagnosing Anaemia in Pregnancy (December 2016). The WHO Reproductive Health Library. Geneva: World Health Organization

21. Fosu MO, Munyakazi L, Nsowah-Nuamah N. Low birth weight and associated maternal factors in Ghana. $J$ Biol Agric Healthcare. 2013;3:7.

22. Ghani A, Mai H, Demmouche A. Epidemiology of low birth weight in the town of Sidi Bel Abbes (West of Algeria): a case-control study. J Nutr Food Sci. 2014;4(278):2.

23. Endalamaw A, Engeda EH, Ekubagewargies DT, Belay GM, Tefera MA. Low birth weight and its associated factors in Ethiopia: a systematic review and meta-analysis. Ital J Pediatr. 2018;44 (1):141. doi:10.1186/s13052-018-0586-6

24. Oladeinde HB, Oladeinde OB, Omoregie R, Onifade AA. Prevalence and determinants of low birth weight: the situation in a traditional birth home in Benin City, Nigeria. Afr Health Sci. 2016;15 (4):1123-1129. doi:10.4314/ahs.v15i4.10

25. Louis B, Steven B, Margret N, et al. Prevalence and factors associated with low birth weight among teenage mothers in new Mulago hospital: a cross sectional study. J Health Sci (El Monte). 2016;4:192.

26. Shaziya SRB, Ramya B, N.S. S. Morbidities and survival outcome of admitted low birth weight neonates in non-teaching district hospital SNCU. Int J Contemp Pediatr. 2016;3:828-832. doi:10.18203/23493291.ijcp20161860

27. Desta SA, Damte A, Hailu T. Maternal factors associated with low birth weight in public hospitals of Mekelle city, Ethiopia: a case-control study. Ital J Pediatr. 2020;46(1):1-9. doi:10.1186/ s13052-020-00890-9

28. CHOP. Low birth weight. Available from: https://www.chop.edu/con ditions-diseases/low-birthweight. Accessed 2017.

29. NIH. What are some factors that make a pregnancy high risk? 2017. Available from: https://www.nichd.nih.gov/health/topics/high-risk /conditioninfo/factors\#f12. Accessed 2017.

30. Yuan F, Qian D, Huang C, et al. Analysis of awareness of health knowledge among rural residents in Western China. BMC Public Health. 2015;15(1):55. doi:10.1186/s12889-015-1393-2

31. Tarekegn SM, Lieberman LS, Giedraitis V. Determinants of maternal health service utilization in Ethiopia: analysis of the 2011 Ethiopian Demographic and Health Survey. BMC Pregnancy Childbirth. 2014;14(1):161. doi:10.1186/1471-2393-14-161

32. Thomre P, Borle A, Naik J, Rajderkar S. Maternal risk factors determining birth weight of newborns: a tertiary care hospital based study. Int J Recent Trends Sci Technol. 2012;5(1):3-8.

33. Talie A, Taddele M, Alemayehu M. Magnitude of low birth weight and associated factors among newborns delivered in Dangla primary hospital, Amhara regional state, Northwest Ethiopia, 2017. J Pregnancy. 2019;2019.

34. Shrestha S, Shrestha S, Shakya Shrestha U, Gyawali K. Predictors of low birth weight at Lumbini Provincial Hospital, Nepal: a Hospital-Based Unmatched Case Control Study. Adv Prev Med. 2020;2020:1-7. doi:10.1155/2020/8459694

35. PregnancyCorner. Low birth weight; 2017. Available from: https:// www.pregnancycorner.com/giving-birth/complications/low-birthweight.html. Accessed 2017.

36. Voldner N, Frey Frøslie K, Godang K, Bollerslev J, Henriksen T. Determinants of birth weight in boys and girls. Hum Ontogenetics. 2009;3(1):7-12. doi:10.1002/huon.200900001

37. Abebaw D. Prevalence and Associated Factors of Low Birth Weight Among Newborn Babies in Dessie Town Health Institutions Amhara Region, Ethiopia, 2017. Addis Ababa University; 2017. Available from: http://etd.aau.edu.et/bitstream/ handle/123456789/6869/Desalegn\%20Abebaw.pdf? sequence= 1\&isAllowed=y. Accessed November 13, 2020. 


\section{Publish your work in this journal}

The Journal of Multidisciplinary Healthcare is an international, peerreviewed open-access journal that aims to represent and publish research in healthcare areas delivered by practitioners of different disciplines. This includes studies and reviews conducted by multidisciplinary teams as well as research which evaluates the results or conduct of such teams or healthcare processes in general. The journal covers a very wide range of areas and welcomes submissions from practitioners at all levels, from all over the world. The manuscript management system is completely online and includes a very quick and fair peer-review system. Visit http://www.dovepress.com/testimonials. php to read real quotes from published authors. 